\title{
An on-line dashboard to facilitate monitoring of provincial I CU bed occupancy in Alberta, Canada
}

\author{
Reza Shahpori ${ }^{1,2}$, Noel Gibney ${ }^{2,3}$, Nancy Guebert ${ }^{2}$, Caroline Hatcher ${ }^{1,2}$, David Zygun ${ }^{2,3}$ \\ 1. Department of Critical Care Medicine, Alberta Health Services, Calgary, Alberta. Canada. 2. Alberta Health Services, \\ Critical Care Clinical Network, Canada. 3. Division of Critical Care Medicine, Alberta Health Services, Edmonton, Alberta. \\ Canada.
}

Correspondence: Reza Shahpori. Address: Clinical Informatics Lead, Critical Care Administration, Room 0454, 3134, Hospital Dr. NW, McCaig Tower, Calgary, Alberta, Canada T2N2T9. E-mail: Reza.shahpori@Albertahealthservices.ca

Received: J une 13, 2013

DOI : $10.5430 /$ jha.v3n1p47
Accepted: September 28, 2013 Online Published: October 10, 2013

URL: http://dx.doi.org/10.5430/jha.v3n1p47

\begin{abstract}
Intensive Care Unit (ICU) beds are among the most valuable hospital resources for which demands periodically exceed supplies. Hence monitoring and management of utilization of these resources is essential for providing an efficient and equitable service. The purpose of this article is to describe the design, development and utilization of a dashboard for the measurement of occupancy and management of capacity of a provincial network of ICUs. The dashboard utilizes the exiting hospital data sources and infrastructure to provide a timely snapshot of bed utilization as well as a historical view of unit occupancy and enables simulation scenarios for capacity planning in a dispersed geographical location. This information is used by administration for managing the scarce ICU resources and helping with standardization of admit and discharge processes to and from intensive care units in order to enhance efficiency. In our case, the existing hospital information systems proved to contain reliable data and the existing information technology infrastructure owned proper resources to be accessed to develop such valuable tool. Such dashboard presents necessary information to facilitate understanding of capacity and bed utilization and can help create a sense of community and standardization of critical care services which would eventually contribute to a more equitable and efficient health system.
\end{abstract}

\section{Key words}

Critical care, Capacity management, Dashboard, Business intelligence, Information dissemination, Hospital information system

\section{I ntroduction}

Delayed or refusal of admission to Intensive Care Unit (ICU) due to bed unavailability is a common issue ${ }^{[1]}$. ICU beds are among the most valuable hospital resources for which demands periodically exceed supplies, resulting in rationing of such resource $^{[2]}$. Several studies have evaluated the adverse outcomes associated with admission delay or refusal to admit to ICU due to bed unavailability ${ }^{[2-5]}$. Premature discharge from ICU to other care units or transfer to step-down units is a common response at times of high occupancy which is also reported to be associated with an increased risk of readmission or hospital mortality ${ }^{[6]}$. The aging population, budgetary concerns and human resource shortages are predicted to aggravate this issue in the coming years ${ }^{[7]}$. 
Developments of ICU outreach programs or Medical Emergency Teams enable an ICU team to visit patients with sudden clinical deterioration. As a quality improvement initiative, these programs, are usually aimed at reduction of negative effects of delayed admissions. However the effectiveness of such programs on the shortage of ICU beds is still unclear ${ }^{[8]}$. Transfer of critically ill patients to other nearby ICUs or inter-facility transfers is another short term solution which is also reported to be associated with adverse outcomes ${ }^{[9]}$.

These issues, the associated outcomes and the cascading effects of delayed admissions or discharges are making bed flow management an essential administrative responsibility among health authorities ${ }^{[1-6]}$. Timely information regarding bed availability is an immediate requirement to intelligently manage admission, discharge and transfers to and from ICUs. Furthermore, timely availability of such information allows for shared accountability for utilizing ICU scarce resources and facilitates future resource planning.

Following the 2009 H1N1 pandemic ${ }^{[24]}$, it became evident that the Critical Care community required a fast and reliable way to obtain essential information with respect to unit occupancy and bed availability in ICU's throughout the province of Alberta. During this time understanding our bed utilization seemed to be the first step in determining variability in ICU bed distribution across the province and the factors that mitigate it such as established referral patterns, variable occupancy rates, efficiency in utilization of scarce resources and demographic pressures.

Critical Care services in Alberta with a population of 3.8 million and area of 661,000 square kilometers is delivered mostly in the two large cities of Edmonton and Calgary and five smaller cities throughout the province. Based on the success of a zonal near-real-time dashboard indicating the occupancy of ICU beds in Calgary's five adult ICU units (see Figure 1), the newly established Alberta Health Services Critical Care Clinical Network (CCCN) decided to develop similar functionality covering all the Critical Care units throughout the province.

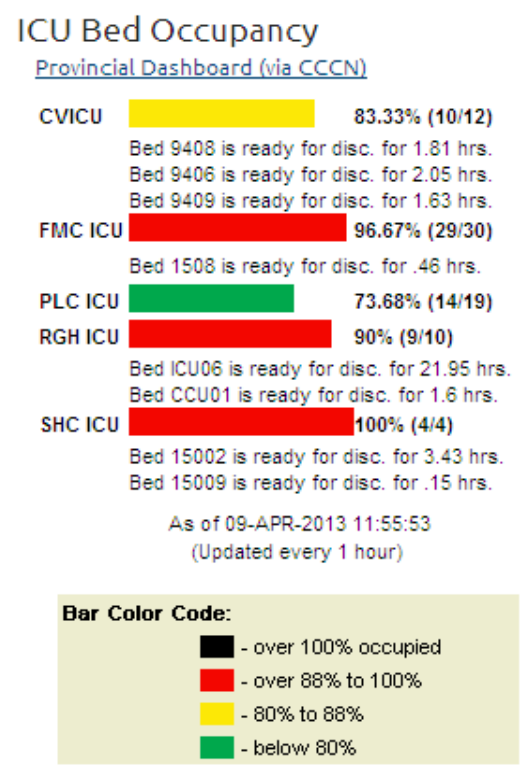

Figure 1. Zonal occupancy dashboard, Calgary

\section{Planning and requirements}

Inspired by the value of a well-established regional dashboard in Calgary for bed management (see Figure 1), the CCCN leadership felt that such a tool would be of value at a provincial level. Discussions were held to determine the possibility of developing a provincial dashboard. The technical feasibility study determined that the appropriate and timely data existed in the hospital Admit, Discharge and Transfer (ADT) data sources which could be used for such purposes. It was decided 
to benefit from the existing Information Technology infrastructure throughout the province to quickly and with minimal cost develop an evolutionary application in multiple phases.

The CCCN solicited support from the executive leadership of Alberta Health Services to facilitate data access. A project plan was developed and the CCCN budgeted $\$ 20,000$ to purchase the required development software license and to hire a practicum Information Technology student for six months. The medical and administrative leaders in each of the ICUs were contacted to gather demographic information and to understand how their units and their beds could be identified in the ADT systems. Data connections between the ADT systems and a local database were established and the queries were developed. After Calgary data proved to be accurate, Edmonton sites were added followed by units from the rest of the province.

The first requirement for this development was to access a hybrid of data repositories hosting ADT transactions for 17 hospitals in seven major cities across the province. Although these repositories were developed for administrative purposes and were dissimilar in data dictionary and database structure, they were considered to provide timely and quality data for development of the bed-occupancy dashboard.

A reliable local database to consolidate the acquired ADT data and the unit specific demographics data was the second requirement. In this database a small table would hold the demographics for each of the units along with the maximum number of funded beds and type of unit (e.g. Adult- Multi-System ICU, Cardio Vascular ICU, Pediatric ICU, Cardiac Care Unit, and Neonatal ICU). A scheduled hourly job in this database, which was to be hosted on the existing Calgary ICU data warehouse ${ }^{[10]}$, would execute a stored procedure, querying the different repositories, to get a count of current patients in each of the ICU units and update the number of occupied beds in a table in the local database.

The third requirement was a Business Intelligence (BI) server which would access the local table and present its data in a user-friendly graphical format. For this purpose the provincial enterprise BI tool, TABLEAU ${ }^{[11]}$, which is managed and maintained by the provincial Data Integration - Measurement \& Reporting (DIMR) services, was used.

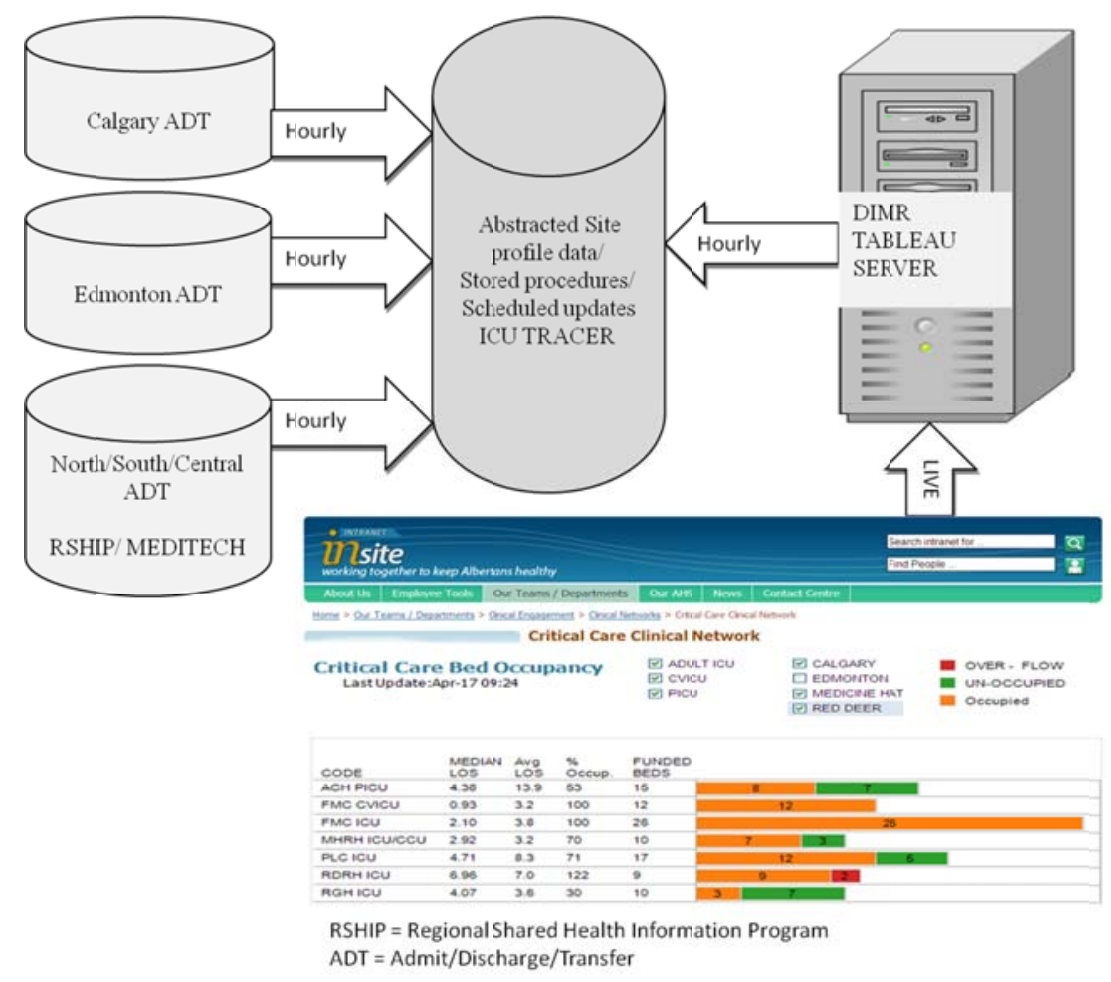

Figure 2. Dashboard architecture 
The final requirement was a method to present the dashboard graphical interface in an easy-to-access format, most visible to the users who would need the information. It was decided to use the home page of the CCCN website which was hosted on the provincial intranet web server, "Insite” (see Figure 2).

Due to the geographic disparity and the variance in admit and discharge processes in the province as well as the differences in information systems' architectures and data entry procedures, the project required evolutionary development and delivery, an iterative approach and adaptive planning, on the other hand, a rapid and flexible response to imminent changes in capacity required a continuous development cycle. For these reasons the agile software development methodology ${ }^{[12]}$ would enable quick development and utilization of the most urgently needed functionality of the dashboard followed by further developments in successive stages. The first deliverable was to be the "current bed occupancy indicator view". This view would update the unit occupancy rate once an hour. Provisions would need to be made for further additions, expansions, enhancements and more complicated functionalities such as re-admission rates, historical views and addition of cardiac care and neonatal ICUs to be addressed in future phases.

\section{Development}

In the first phase of the development which took three months, the framework and the database links and queries were established and the first dashboard functionality, the current bed occupancy indicator view was developed.

\subsection{Dashboard current view}

The dashboard current view resulting from the first phase of development which is now accessible on the home page of the CCCN intranet website throughout the province contains 20 adult, cardiovascular and pediatric ICU units from seven cities. Color coded bars indicate occupied, un-occupied and over-flow beds. Pointing the cursor at each bar representing each unit would pop up a tool-tip with demographics and contact information for that unit. A high or low median and average Length of Stay (LOS), once adjusted for the case mix, has a great value in benchmarking, while a big difference between median and average LOS is an indication of one or more long stay patients. Comparison of average and median LOS among our sites has already revealed differences in practice which requires standardization and may potentially translate to higher equity of patient care in our province. For simplicity the dashboard content can be filtered based on unit type or location. A mechanism of sending feedback and comments is provided via a web form which is automatically mailed to the webmaster for distribution to the right support party (see Figure 2).

\subsection{Dashboard historical view}

A product of the second development phase includes a historical bed occupancy view containing information demonstrated in graphical format for each unit for the past month and the past year. Selecting a unit on the top graph which is a snapshot of bed occupancy at midnight, would update two line-column graphs immediately underneath (see Figure 3). The double axis graph in the middle (the daily view) indicates the percentage of maximum bed-occupancy for each of the past 31 days on a red line, and the number of hours in each day at maximum occupancy on blue columns.

The bottom double axis graph (the monthly view) indicates the percentage of maximum occupancy for each of the past 12 months on a red line and the number of days with maximum occupancy, on blue columns. In this graph different shades of blue from light to dark are used to indicate average hours per day where the unit was at maximum occupancy. By pointing the cursor at each data point detailed information can be obtained. Another panel in tabular format demonstrates the number of quarterly admits, and median and average LOS for the past one year for the selected unit. The historical view is updated once a day at midnight.

\subsection{Automatic email notifications}

Another feature of the second phase, uses the database functions to send periodic emails to the regional directors 
containing a short message about the situation, when the bed occupancy is at a pre-determined critical level, suggesting the bed availability at other units in the close-by same geographical locations.

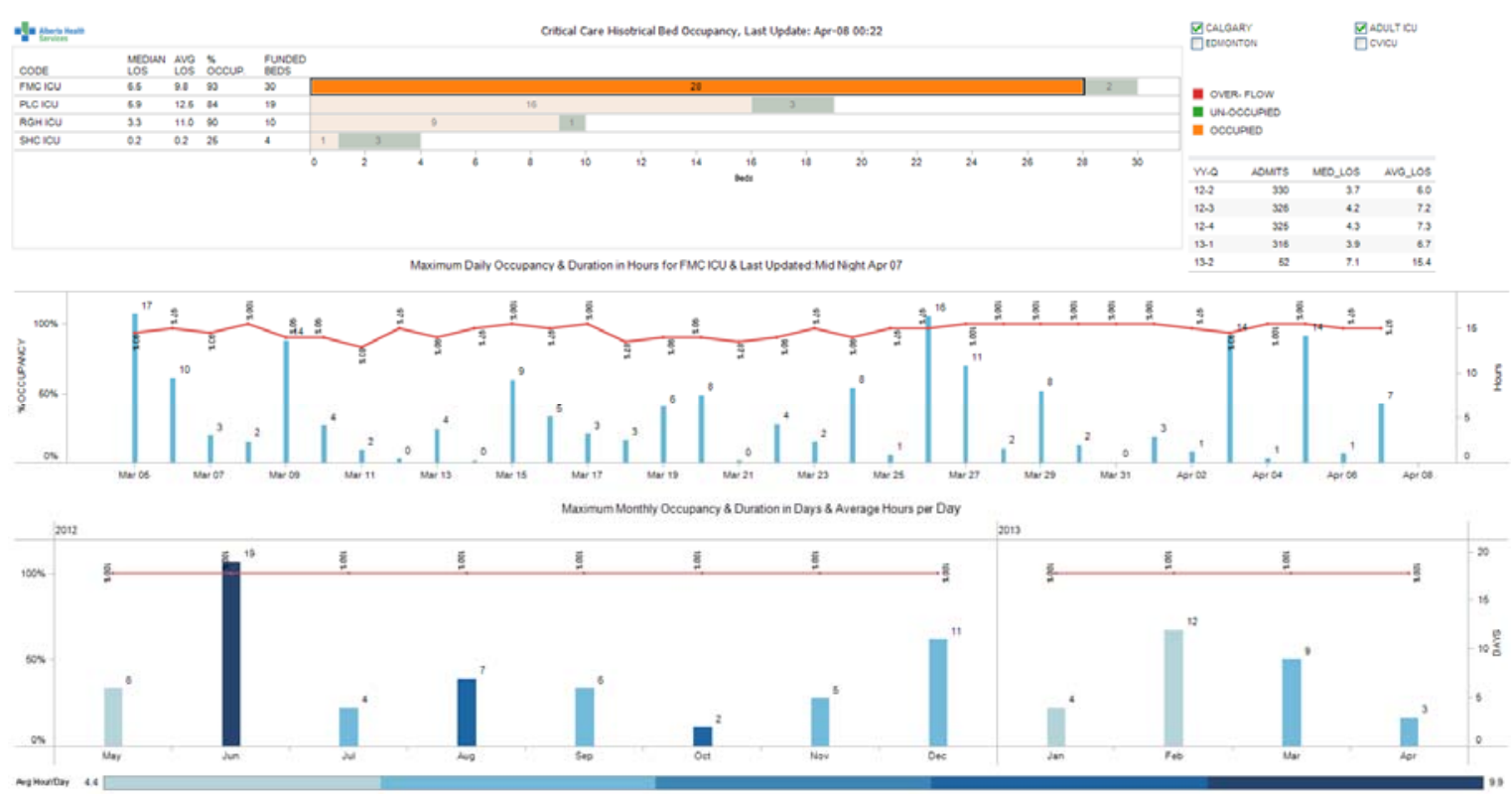

Figure 3. Historical view

\subsection{Simulations}

Another use of this dashboard is to simulate different occupancy scenarios by changing the number of funded beds and regenerating the historical views to mimic different situation on the perceived maximum occupancy in situations where units needed to be expanded or reduced in size. The results would enable the administrators to validate the criticality of the maximum occupancy levels and duration, if the number of funded beds were to be different than the actual. Figure 4 demonstrates the results of two different situations for a unit based on two different funding scenarios. While comparing this information evaluating median and average LOS is crucial for better understanding of occupancy, therefore quarterly median and average LOS is also made available in these views.

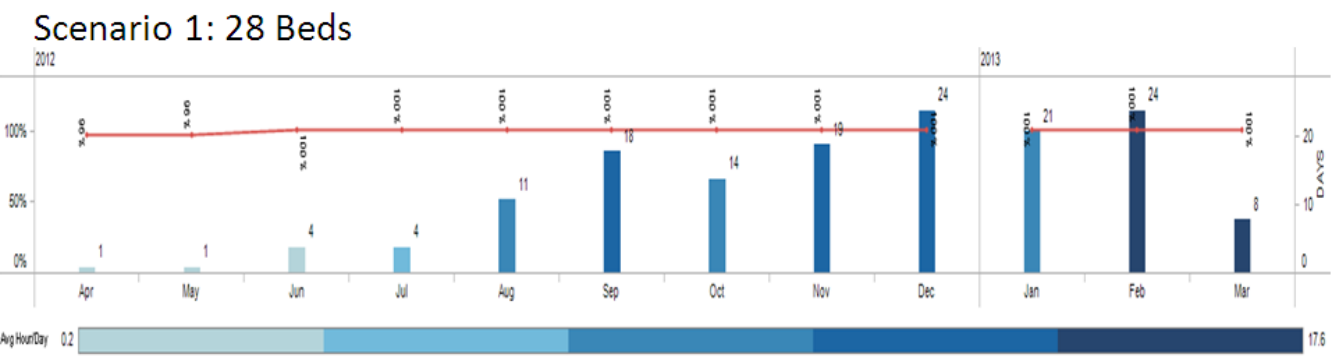

Scenario 2: 25 Beds

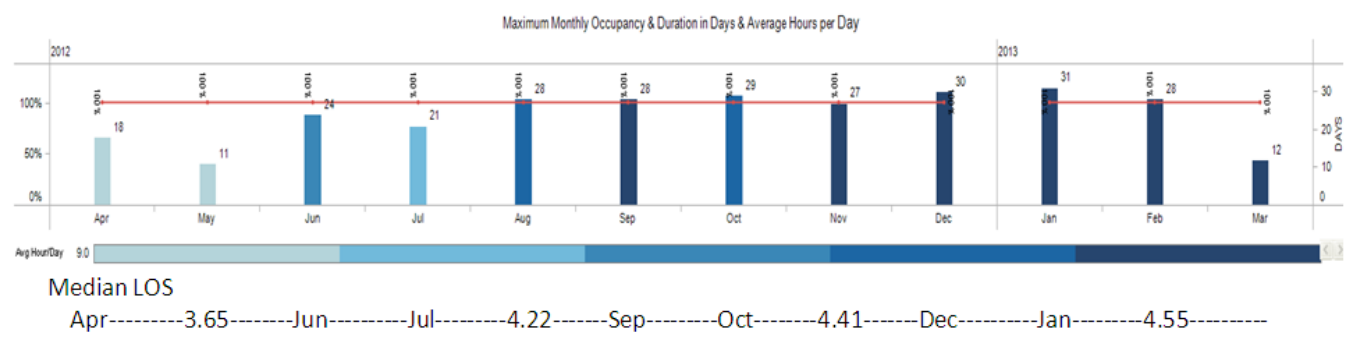

Figure 4. Simulation view 


\section{Discussions}

Lack of ICU beds to admit emergency patients has been cited as one of the reasons for overcrowding the Emergency Rooms (ER) and long wait times that has become a national issue and has contributed to cancellation of elective surgical procedures and has impacted the surgical wait list ${ }^{[13,14]}$. Despite the pressures to reduce the wait times and progresses in some areas, a recent report by Canadian Institute for Health Information (CIHI) suggests that in Canadian ERs, one patient out of ten waits eight or more hours to be seen ${ }^{[15]}$. With an average wait time of four hours Canada actually has the highest ER wait time among the developed countries ${ }^{[15]}$. This issue is encountered throughout the patient journey. Acute care patients mostly of the age 65 and older sometimes will have to wait for more than a month to be moved to a longer term care facility ${ }^{[15]}$. One factor related to the ER wait times or surgical procedures long waiting lists is due to the cascading effects of lack of bed availability in ICUs which in turn might be the effect of shortages in the other areas. An occupancy dashboard can potentially provide an administrative tool to measure, manage and improve the bottlenecks.

A review study by Hanson et al. in 2001 suggested that, despite the rich data environment in critical care and the vast number of opportunities for using data to improve the efficiency of patient care, BI tools and techniques are not widely used to extract actionable information from such data ${ }^{[16]}$. However, more recently and due to the requirements by quality improvement and accreditation campaigns, resulting from the publication of "To Err is human" by the institute of medicine, revealing statistics on the preventable adverse events in the American hospitals ${ }^{[17]}$, the use of BI applications such as dashboards to use data for real time decision making has been exponentially increased.

Rosow et al., in the Health Information and Management System Society (HIMSS) conference in 2002, demonstrated a real-time sophisticated BI application based on the hospital admitting data ${ }^{[18]}$. This management and census control system included a dashboard comparable to that of the air traffic control system. Availability of middle tier BI software and analytics solutions from the giant software vendors such as Oracle ${ }^{[19]}$ and Microsoft ${ }^{[20]}$ Business Intelligence Solutions, IBM Business Analytics and Optimization Services ${ }^{[21]}$ as well as other specialized software vendors and solutions providers such as SAP Analytics Solutions ${ }^{[22]}$ and Micro strategy ${ }^{[23]}$ has made the development of BI applications much easier and faster.

The dashboard we developed using Tableau analytical solution ${ }^{[11]}$ was immediately chosen by Referral, Access, Advice, Placement, Information \& Destination (RAAPID) in the Northern parts of the province for referral management. RAAPID facilitates critical and/or urgent transfers or consultations with a tertiary care facility or a specialist. It allows the right care to be provided at the right place, using real time capacity information from the provincial critical care occupancy dashboard, resulting in enhanced coordination to transport patients.

\section{Conclusion}

The existing hospital information systems may contain valuable data that can be easily accessed to develop a valuable tool such as a unit occupancy dashboard which facilitates understanding of capacity and bed utilization in a dispersed geographical location and can help create a sense of community and standardization of providing critical care services. Our dashboard is used to inform the executive decision makers of resource demands and funding requirements for critical care resources. The dashboard also has established a benchmarking platform for standardization and adjustments to distribution of our services in the province.

An intuitive visual view of bed availability or over-capacity status of our units, would enable our clinicians and administrators to enhance patient flow and reduce the time a patient will have to wait in emergency or operating recovery rooms to be admitted to an ICU bed. This information would also help track bed availability and mange utilization of ICU resources throughout the province in preparation for pandemic planning and emergency response. Such a tool, besides a current view of bed utilization, can be used for historical analytical purposes as well as simulating different scenarios for 
beds closures or unit expansions. Automatic emails assist the administration in understanding the bottlenecks and bed crisis. The end result would be the potentials to improve outcomes as the result of enhanced availability of critical care services.

\section{Conflicts of interest}

None of the authors have financial or professional conflicts of interest that would influence the reporting of this work.

\section{Acknowledgment}

The authors would acknowledge the Alberta Health Services, Critical Care Clinical Network for providing financial assistance for software programming as well as the Critical Care directors and patient care managers for their support and assistance in data validation. We thank Data Integration - Measurement \& Reporting Services for sharing resources and the Information Technology Services for providing access to data sources. Thanks to Mrs. Fariba Mohammadi, Mr. Majid Hashemi and Mr. Alan Delosangeles for assisting with the development.

\section{References}

[1] An observational study to determine the effect of delayed admission to the intensive care unit on patient outcome Critical Care. 2012; 16: R173. http://dx.doi.org/10.1186/cc11650

[2] Sinuff, Tasnim, Kamyar Kahnamoui, Deborah J. Cook, John M. Luce, Mitchell M. Levy. Rationing critical care beds: A systematic review. Critical care medicine. 2004; 32, no. 7: 1588-1597. PMid: 15241106. http://dx.doi.org/10.1097/01.CCM.0000130175.38521.9F

[3] Chalfin, Donald B., Stephen Trzeciak, Antonios Likourezos, Brigitte M. Baumann, R. Phillip Dellinger. Impact of delayed transfer of critically ill patients from the emergency department to the intensive care unit. Critical care medicine. 2007; 35, no. 6: 1477-1483. PMid: 17440421. http://dx.doi.org/10.1097/01.CCM.0000266585.74905.5A

[4] Stelfox, Henry T., Brenda R. Hemmelgarn, Sean M. Bagshaw, Song Gao, Christopher J. Doig, Cheri Nijssen-Jordan, et al. Intensive care unit bed availability and outcomes for hospitalized patients with sudden clinical deterioration. Archives of internal medicine. 2012; 172, no. 6: 467. PMid: 22412076. http://dx.doi.org/10.1001/archinternmed.2011.2315

[5] Clark, Karen, Loretta Brush Normile. Delays in implementing admission orders for critical care patients associated with length of stay in emergency departments in six mid-Atlantic states. Journal of emergency nursing: JEN: official publication of the Emergency Department Nurses Association. 2002; 28, no. 6: 489.

[6] Chrusch, Carla A., Kendiss P. Olafson, Patricia M. McMillan, Daniel E. Roberts, Perry R. Gray. High occupancy increases the risk of early death or readmission after transfer from intensive care. Critical care medicine. 2009; 37, no. 10: 2753. PMid: 19707139. http://dx.doi.org/10.1097/CCM.0b013e3181a57b0c

[7] Angus, D. C., M. A. Kelley, R. J. Schmitz, A. White, J. Popovich Jr. Committee on Manpower for Pulmonary and Critical Care Societies (COMPACCS). Caring for the critically ill patient. Current and projected workforce requirements for care of the critically ill and patients with pulmonary disease: can we meet the requirements of an aging population. JAMA. 2000; 284, no. 21: 2762-2770. PMid: 11105183. http://dx.doi.org/10.1001/jama.284.21.2762

[8] Esmonde, Lisa, Ann McDonnell, Carol Ball, Catherine Waskett, Richard Morgan, Arash Rashidian, et al. Investigating the effectiveness of critical care outreach services: a systematic review. Intensive care medicine. 2006; 32, no. 11: 1713-1721. PMid: 17019547. http://dx.doi.org/10.1007/s00134-006-0380-6

[9] Fan, Eddy, Russell D. MacDonald, Neill KJ Adhikari, Damon C. Scales, Randy S. Wax, Thomas E. Stewart, et al. Ferguson. Outcomes of interfacility critical care adult patient transport: a systematic review. Critical Care. 2005; 10, no. 1: R6. PMid: 16356212. http://dx.doi.org/10.1186/cc3924

[10] Shahpori, Reza, Alan de Los Angeles, Kevin Laupland. Information management framework; a model for clinical departments. Stud. Health Technol. 2009; Inform 143: 81-86.

[11] Tableau Software. 2013 February 04; Available from: URL: http://www.tableausoftware.com/

[12] Highsmith, J., Cockburn, A. Agile software development: The business of innovation. Computer. 2001; 34(9): 120-127. http://dx.doi.org/10.1109/2.947100

[13] Derlet, R. W., Richards, J. R. Overcrowding in the nation's emergency departments: complex causes and disturbing effects. Annals of emergency medicine. 2000; 35(1): 63-68. http://dx.doi.org/10.1016/S0196-0644(00)70105-3 
[14] Costa, A. X., Ridley, S. A., Shahani, A. K., Harper, P. R., De Senna, V., Nielsen, M. S. Mathematical modelling and simulation for planning critical care capacity. Anaesthesia. 2003; 58(4): 320-327. PMid: 12648112. http://dx.doi.org/10.1046/j.1365-2044.2003.03042.x

[15] Canadian Institute for Health Information. 2013 April 09; Available from: URL: http://www.cihi.ca/CIHI-ext-portal/internet/en/Document/health+system+performance/access+and+wait+times/RELEASE_29N OV12

[16] Hanson III, C. William, Bryan E. Marshall. Artificial intelligence applications in the intensive care unit. Critical care medicine. 2001; 29, no. 2: 427. PMid: 11269246. http://dx.doi.org/10.1097/00003246-200102000-00038

[17] Kohn, L. T., J. M. Corrigan, M. S. Donaldson. To err is human: building a safer health system. National Academy of Science, Institute of Medicine. 2002.

[18] Rosow, Eric, Joseph Adam, Kathleen Coulombe, Kathleen Race, Rhonda Anderson. Virtual instrumentation and real-time executive dashboards: Solutions for health care systems. Nursing Administration Quarterly. 2003; 27, no. 1: 58-76. PMid: 12674069. http://dx.doi.org/10.1097/00006216-200301000-00010

[19] Oracle Business Intelligence Enterprise Edition 11g. 2013 April 08; Available from: URL: http://www.oracle.com/us/solutions/business-analytics/business-intelligence/enterprise-edition/overview/index.html

[20] Microsoft Business Intelligence. April 08; Available from: URL: http://www.microsoft.com/en-us/bi/default.aspx

[21] IBM Business Analytics and optimization services. April 08; Available from: URL: http://www-935.ibm.com/services/us/gbs/business-analytics/?cm_re=masthead-_-business-_-bzn-bao

[22] SAP Analystics Solutions. April 08; Available from: URL: http://www54.sap.com/solutions/analytics/strategy.html

[23] Microstrategy. April 08; Available from: URL: http://www.microstrategy.com/

[24] Shahpori, R., Stelfox, H. T., Doig, C. J., Boiteau, P. J., Zygun, D. A. Sequential Organ Failure Assessment in H1N1 pandemic planning. Critical care medicine. 2011; 39(4): 827-832. PMid: 21263327. http://dx.doi.org/10.1097/CCM.0b013e318206d548 